\title{
Publisher Correction: A small and round heliosphere suggested by magnetohydrodynamic modelling of pick-up ions
}

Merav Opher (D), Abraham Loeb, James Drake and Gabor Toth

Correction to: Nature Astronomy https://doi.org/10.1038/s41550-020-1036-0, published online 16 March 2020.

In the version of this Article originally published, the temperatures in Fig. $3 \mathrm{~g}$ were incorrectly listed as $1.00 \times 10^{-6}$ and $2.20 \times 10^{-7} \mathrm{~K}$; they should have been $1.00 \times 10^{6} \mathrm{~K}$ and $2.20 \times 10^{7} \mathrm{~K}$. Similarly, the temperatures in Fig. $3 \mathrm{~h}$ were incorrectly listed as $2.00 \times 10^{-4} \mathrm{~K}$ and $5.20 \times 10^{-5} \mathrm{~K}$; they should have been $2.00 \times 10^{4} \mathrm{~K}$ and $5.20 \times 10^{5} \mathrm{~K}$. This has now been corrected.

Published online: 5 May 2020

https://doi.org/10.1038/s41550-020-1118-z

๑ The Author(s), under exclusive licence to Springer Nature Limited 2020 